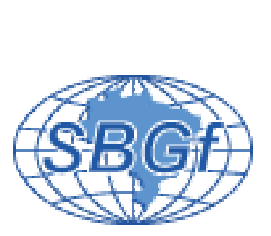

\title{
Estimativa da espessura crustal na região limítrofe dos Estados de Goiás e Mato Grosso, Brasil.
}

Takato NAKAYOSHI, Observatório Sismológico/IG/UnB

George Sand FRANÇA, DFTE/UFRN

\section{Copyright 2004, SBGf - Sociedade Brasileira de Geofísica}

Este texto foi preparado para a apresentação no I Simpósio de Geofísica da Sociedade Brasileira de Geofísica, São Paulo, 26-28 de setembro de 2004. Seu conteúdo foi revisado pela Comissão Tecno-científica do I SR-SBGf mas não necessariamente representa a opinião da SBGf ou de seus associados. E proibida a reprodução total ou parcial deste material para propósitos comerciais sem prévia autorização da SBGt

\section{Resumo}

A espessura crustal na região limítrofe dos Estados de Goiás e Mato Grosso foi estimada utilizando-se a função do receptor. Os dados foram obtidos pela Estação ARAB no ano de 1998. Foram utilizados 10 eventos para o cálculo da espessura crustal e obteve-se o valor médio de $34 \mathrm{~km}$. Também foi obtido um valor preliminar para o coeficiente de Poisson de 0,26. Para estas estimativas foi utilizado o valor de $\mathrm{Vp} / \mathrm{Vs}$ de 1,76 (Assumpção et al.,2003), apesar de ter sido encontrado um valor de 1,81. Um modelo de velocidade empírico utilizando esta espessura e quatro camadas foi elaborado e, através deste modelo, um sismograma sintético foi obtido.

\section{Introdução}

Este trabalho apresenta os resultados preliminares da estimativa da espessura crustal na região limítrofe dos Estados de Mato Grosso e Goiás. Os dados utilizados foram obtidos pela Estação ARAB no ano de 1998. A Função do Receptor tem sido amplamente utilizada com este propósito (Phinney, 1964; Burdick \& Langston, 1977; Langston, 1979; Assumpção et al., 2002; Assumpção et al., 2003; França, 2003). Esta técnica consiste em analisar isoladamente a onda $\mathrm{P}$ de telessismos e fases desta onda $\mathrm{P}$ convertidas, por exemplo em $\mathrm{S}$, em uma interface horizontal sob a estação. Pode ser utilizada tanto a amplitude como o tempo (tPs - tP). Este trabalho apresenta os resultados preliminares obtidos através da diferença dos tempos de chegada. A Figura 1 apresenta o raio sísmico para as diferentes fases que atravessam uma única interface horizontal e sua respectiva função do receptor. Os sismogramas contêm informações da fonte (origem), das estruturas sob a estação, da resposta do instrumento e de atenuações sofridas no percurso das ondas sísmicas. A Função do Receptor tem como objetivo isolar as informações das estruturas geológicas, ou seja, obter um sismograma somente com a resposta da estrutura sob a estação.

A Estação Sismográfica ARAB foi instalada na Província Tocantins (Almeida et al., 1981) que se localiza na porção central do Brasil e representa um grande orógeno formado entre três grandes blocos continentais: os crátons Amazônico, São Francisco/Congo e Paranapanema. A Província Tocantins constitui-se por
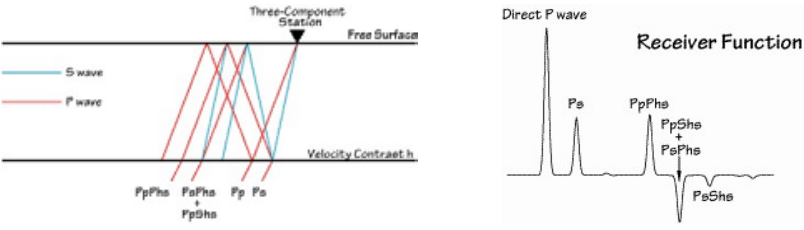

Figura 1 - Diagrama simplificado dos raios sísmicos de diferentes fases e suas respectivas função do receptor (Ammon et al.. 1990).

três importantes faixas dobradas: as faixas Araguaia, Paraguaia e Brasília. Nas proximidades da estação encontram-se também rochas sedimentares da Bacia do Paraná. A estação sismográfica foi instalada nos ortognaisses do oeste de Goiás, onde próximo também afloram rochas da Formação Araguaia (Figura 2). A Estação Sismográfica ARAB foi instalada pela equipe do Observatório Sismológico de Brasília e operou com um registrador QUANTERRA QDAS 4120 e sensor GURALP. Localiza-se no Estado de Mato Grosso, no Município Araguaia. A coordenada da estação é $15,6642^{\circ} \mathrm{S}$ e $51,8073^{\circ} \mathrm{W}$.

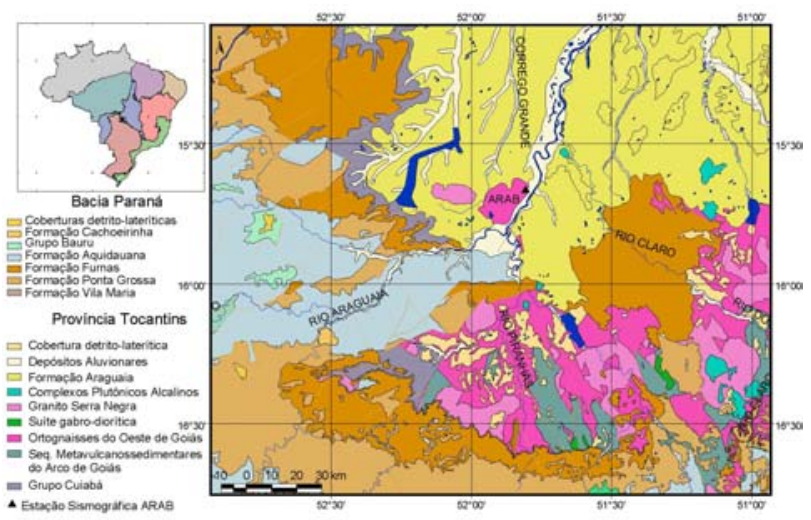

Figura 2 - Geologia da região próxima à Estação $A R A B$ elaborado com base no mapa geológico do Brasil na escala 1:2.500.000.

\section{Metodologia/ Problema Investigado}

Os dados utilizados para a elaboração deste trabalho foram gerados pela Estação ARAB no ano de 1998 (Tabela 1). Para a seleção dos dados utilizaram-se os seguintes critérios: 1) $\mathrm{m}_{\mathrm{b}}>5$ e $50^{\circ}<\Delta<150^{\circ}$ e 2) $\mathrm{m}_{\mathrm{b}} \geq$ 4.5 e $17^{\circ}<\Delta<50^{\circ}$, onde $\Delta$ é a distância entre a estação e o epicentro. Dentro desta seleção foram escolhidos apenas os eventos que apresentam a chegada da onda $P$ bem evidente. 
Com a Função do Receptor foi possível obter para cada evento a diferença no tempo de chegada da onda $P$ convertida em S e da onda P (tPs - tP). Com esta diferença foi possível calcular a espessura crustal sob a Estação ARAB (Tabela 1).

Para os cálculos da espessura crustal e da razão Vp/Vs utilizou-se as fórmulas (Zandt et al.,1995):

$$
t P s-t P=\frac{h}{V_{P}}\left[\frac{V_{P}}{V_{S}}\left(1-p^{2} V_{S}^{2}\right)^{1 / 2}-\left(1-p^{2} V_{P}^{2}\right)^{1 / 2}\right]
$$

$$
\frac{V_{p}}{V_{s}}=\left\{\left(1-p^{2} V_{p}^{2}\right)\left[2\left(\frac{t_{p s}-t_{p}}{t_{p_{p} p_{m s}}-t_{p_{s}}}\right)+1\right]^{2}+p^{2} V_{p}^{2}\right\}^{1 / 2}
$$

Com os eventos de azimute próximos (intervalos de $10^{\circ}$ ) e com parâmetro de raio igual (ou com diferença em até $0,3 \mathrm{~s} /{ }^{\circ}$ ) fez-se o empilhamento dos sinais obtidos com a Função do Receptor.

Com o traço empilhado mostrado na Figura 4 e com base no modelo inicial apresentado na Tabela 2 fez-se a inversão. $A$ razão $V_{P} / V_{S}$ utilizada foi de 1,76 (Assumpção et al., 2003) e para o cálculo da razão de Poisson utilizou-se a fórmula (Zandt et al.,1995):

$$
\sigma=\frac{1-0,5 \cdot\left(\frac{V_{P}}{V_{S}}\right)^{2}}{1-\left(\frac{V_{P}}{V_{S}}\right)^{2}}
$$

\section{Resultados}

A Tabela 1 apresenta os resultados da estimativa da espessura crustal sob a Estação ARAB. Para esta estimativa foram utilizados dois valores de $\mathrm{Vp} / \mathrm{Vs}$. Com valor de 1,76 obtido por Assumpção et al. (2003), a espessura média calculada foi de $32,5 \mathrm{~km}$. Com o valor de $V p / V s$ de 1,71 obtido por Soares (informação verbal) para a região de Cavalcante (GO), a espessura crustal média encontrada foi de $34,7 \mathrm{~km}$. A velocidade da onda $P$ utilizada para o cálculo da espessura da crosta foi de 6,3 $\mathrm{km} / \mathrm{s}$ (Berrocal et al., 2003). A Figura 3 mostra a função do receptor para o evento número 6 da Tabela 1 .

Os valores de $\mathrm{Vp} / \mathrm{Vs}$ foram obtidos por apenas três traços, por isso não foram utilizados na estimativa da espessura crustal.

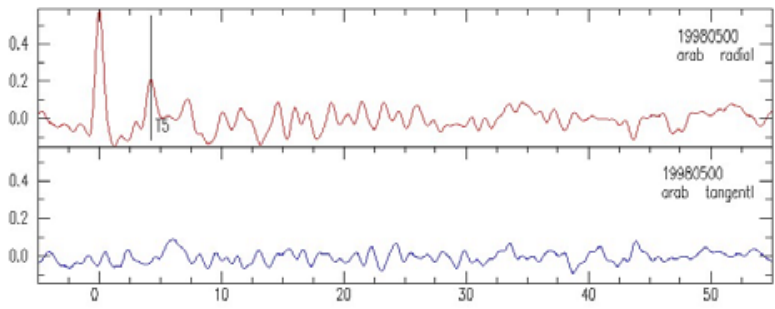

Figura 3: Função do receptor para o terremoto ocorrido no Peru no dia 19 de fevereiro de 1998, com magnitude $5,7 m_{b}$.
Com o empilhamento dos eventos 2 e 3 da Tabela 1 (Figura 4) e com o modelo inicial apresentado na Tabela 2 fez-se a inversão (Figura 5). O valor da razão de Poisson através da equação (3) obtido foi 0,26 . Os parâmetros utilizados no modelo inicial foram a espessura da crosta de $34 \mathrm{~km}$, a razão $\mathrm{Vp} / \mathrm{Vs}$ de 1,76 , a razão de Poisson de 0,26 e a velocidade média da onda $P$ na crosta de $6,3 \mathrm{~km} / \mathrm{s}$. O número de camadas e as velocidade da onda $\mathrm{P}$ em cada uma delas foram adotados empiricamente.

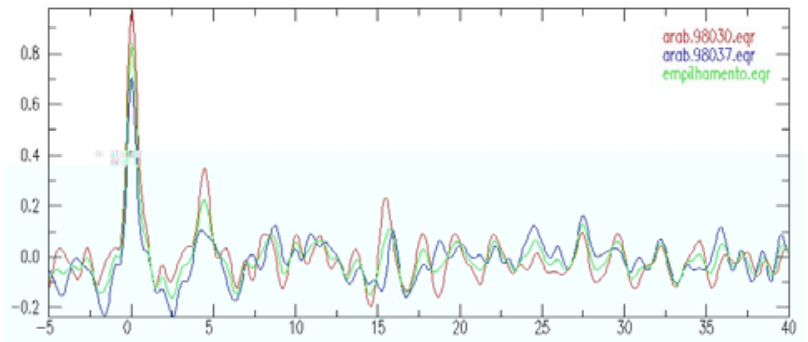

A)

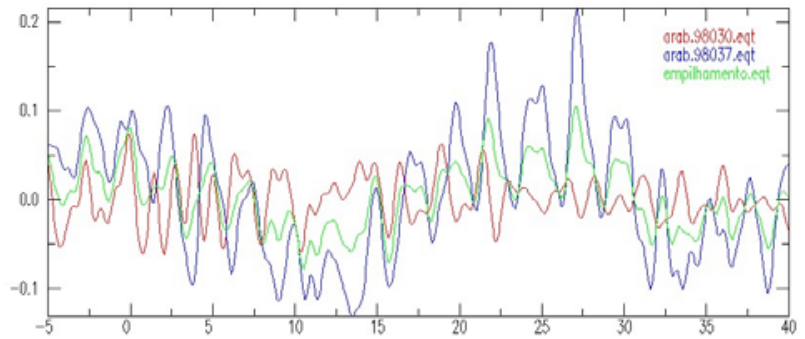

B)

Figura 4 - Empilhamento (traço verde) para os eventos 2 (vermelho) e 3 (azul) da Tabela 1. A) Empilhamento da componente radial e B) tangencial.
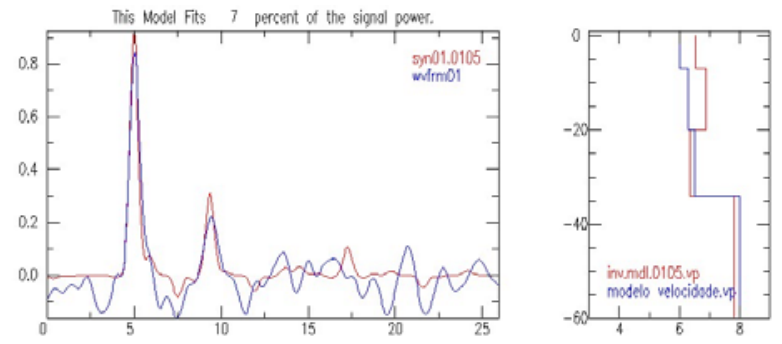

Figura 5 - Formas de onde da Função do Receptor do empilhamento dos eventos 2 e 3 (azul) da Tabela 1 e o sismograma sintético elaborado a partir do modelo inicial (vermelho). A direita é apresentado o modelo inicial utilizado (azul) e o ajuste do sismograma real para este modelo.

\section{Discussão e Conclusões}

O cálculo da espessura crustal foi feito utilizando-se dois valores de $\mathrm{Vp} / \mathrm{Vs}$. O primeiro foi obtido por Assumpção et al. (2003) na Estação PAZB, onde a espessura da crosta é de 33,1 $\pm 1,2 \mathrm{~km}$ e localiza-se próximo à Estação $A R A B$. O segundo valor de $\mathrm{Vp} / \mathrm{Vs}$ foi 
obtido por Soares (informação verbal) para a região que apresenta valores altos de anomalia gravimétrica, onde a espessura da crosta na região de Cavalcante (GO) é de $34 \mathrm{~km}$ na porção leste da linha sísmica levantada. Apesar de estarem mais distantes, a Estação $A R A B$ e a região de Cavalcante estão em áreas onde as anomalias gravimétricas são próximas, por isso o valor $\mathrm{Vp} / \mathrm{Vs}$ obtido nessa região foi também utilizado.

Mesmo utilizando dois valores de $\mathrm{Vp} / \mathrm{Vs}$, as estimativas preliminares obtidas para a espessura da crosta são próximas.

Os valores de $\mathrm{Vp} / \mathrm{Vs}$ obtidos para a região em estudo ainda não são unânimes. França (2003) obteve 1,69 utilizando a Estação PAZB. Como os dados desta mesma estação, Assumpção et. al (2003) obtiveram 1,76 . Apesar de serem preliminares os resultados obtidos neste trabalho, os valores indicam que a razão $\mathrm{Vp} / \mathrm{Vs}$ de 1,76 seja mais apropriada. Diferente do valor de 1,71 obtido para a região de Cavalcante, que mesmo apresentando uma resposta gravimétrica equivalente, está inserida em um contexto geológico distinto.

O modelo de velocidade adotado deve ser ainda refinado com mais informações, pois a área apresenta um contexto geológico muito mais complexo.

Os valores obtidos para a espessura da crosta sob a Estação $A R A B$ através da função do receptor são preliminares, pois foram obtidos com poucos dados. Porém, não difere muito dos resultados obtidos nas regiões próximas.

\section{Agradecimentos}

Os autores agradecem a José Eduardo Pereira Soares pelas informações cedidas e a discussão dos resultados obtidos que enriqueceram o trabalho.

\section{Referências}

Almeida, et al. (03 co-authors), 1981. Brazilian Structural Provinces: an introduction. Earth Sciences Review, 17: 19.

Ammon, C. J., G. E Randall \& G. Zandt, 1990. On the nonuniqueness of receiver function inversions. J. Geophys. Res, 95: 5303-15318.

Assumpção, et al. (06 co-authors), 2003. Seimic Studies in Central Brazil, using receiver function, surface wave dispersion and teleseismic tomography: evidence for the neoproterozoic San Franciscan Plate. Submitted to Tectonophysics.

Assumpção, M., D. James \& J. A. Snoke, 2002. Crustal thickness is SE Brazilian Shield with receiver function: implications for isostatic compensatin, J. Geophys. Res., 107, B1, doi:10.1029/2001JB000422, ESE2-11.

Berrocal, et al. (06 co-authors), 2003. Deep seismic refraction and gravity crustal model and tectonic deformation in Tocantins Province, central Brazil. Tectonophys., Seismix 2003 special issue, submitted.
Burdick, L. J. \& C. A. Langston, 1977. Modeling crustal structure through the use of converted phases in teleseismic body-wave forms. Bulletin of the Seismological Society of America, 67(3):677-691.

França, G. S. 2003. Estrutura da crosta no sudeste e centro-oeste do Brasil com a função do receptor. Tese de Doutorado. Instituto de Astronomia, Geofísica e Ciências Atmosféricas/USP (São Paulo, SP, Brasil), 143p.

Langston, C. A. 1979. Structural under Mount Rainier, Washington, inferred from teleseismic body waves. J. Geophys. Res., 84(B9): 4749-4762.

Phinney, R. A., 1964. Structure of the Earth's crust from spectral behavior of long-period body waves. J. Geophys. Res., 69(14): 2997-3017.

Soares, J.E.P., R. A. Fuck, J. Berrocal \& R. M. Vilhena. Geophysical evidence of Amazon Craton subduction in central Brazil: a new insight into Tocantins Province evolution. Em preparação.

Soares, J.E.P, J. Berrocal \& R. A. Fuck, 2003. Seismic crustal structure in central Brazil. 8th Internat. Cong. of the Brazilian Geophy. Soc., Rio de Janeiro Expanded Abstract Volume.

Zandt, G., S. C. Myers \& T. C. Wallace, 1995. Crustal and mantle across the Basin and Range - Colorado Plateu boundary at $37^{\circ} \mathrm{N}$ latitude and implications for Cenozoic extensional mechanism. J. Geophys. Res., 100(B6): 10529-10548. 
Tabela 1 - Eventos registrados pela estação ARAB sele

dos para executar a Função do Receptor.

\begin{tabular}{|c|c|c|c|c|c|c|c|c|c|c|c|c|c|c|c|c|}
\hline & Ano & Juliano & Hora & Min & Seg & Lat & & Prof & $\mathrm{m}_{\mathrm{b}}$ & Distância $\left(^{\circ}\right)$ & $\begin{array}{c}\text { Back } \\
\text { Azimute }\end{array}$ & $\begin{array}{c}p \\
\left(s /{ }^{\circ}\right)\end{array}$ & $\begin{array}{c}\text { tPs - tP } \\
(s)\end{array}$ & $\begin{array}{c}\text { Espessura }^{1} \\
(\mathbf{k m})\end{array}$ & $\begin{array}{c}\text { Espessura }^{2} \\
(\mathbf{k m})\end{array}$ & Vp/Vs \\
\hline 1 & 1998 & 063 & 17 & 26 & 47,4 & $-17,501$ & -6 & 131,0 & 5,1 & 17,034 & 261,3 & 11,0 & 4,24816 & 33,02766 & 30,97941 & \\
\hline 2 & 1998 & 037 & 06 & 37 & 12,9 & $-22,742$ & -7 & 58,0 & 5,3 & 18,648 & 245,0 & 10,9 & 4,42199 & 34,47594 & 32,33491 & \\
\hline 3 & 1998 & 030 & 12 & 16 & 07,8 & $-24,118$ & -7 & 44,0 & 6,3 & 19,432 & 241,4 & 10,9 & 4,43052 & 34,54244 & 32,39729 & 1,55 \\
\hline 4 & 1998 & 029 & 03 & 13 & 39,4 & $-15,649$ & -7 & 133,0 & 5,1 & 19,660 & 267,2 & 10,8 & 4,56205 & 35,66647 & 33,44851 & 1,82 \\
\hline 5 & 1998 & 065 & 03 & 56 & 16,4 & $-10,859$ & -7 & 33,0 & 5,1 & 22,691 & 279,3 & 10,5 & 4,29011 & 33,81111 & 31,70031 & \\
\hline 6 & 1998 & 050 & 03 & 21 & 45,6 & $-10,675$ & -7 & 155,0 & 5,7 & 22,676 & 279,8 & 9,14 & 4,26429 & 34,6993 & 32,50016 & \\
\hline 7 & 1998 & 062 & 02 & 24 & 45,4 & 14,371 & -9 & 76,0 & 5,6 & 49,295 & 305,2 & 7,62 & 4,26745 & 35,72298 & 33,42987 & 1,81 \\
\hline 8 & 1998 & 034 & 03 & 02 & 00,8 & 16,023 & -9 & 33,0 & 5,9 & 53,994 & 303,6 & 7,3 & 4,33913 & 36,50885 & 34,16003 & \\
\hline 9 & 1998 & 047 & 23 & 53 & 19,5 & 52,666 & -3 & 10,0 & 6,2 & 69,832 & 11,65 & 6,15 & 4,33929 & 37,10354 & 34,69977 & \\
\hline 10 & 1998 & 084 & 03 & 12 & 24,7 & $-62,876$ & 14 & 10,0 & 6,6 & 99,923 & 189,8 & 4,46 & 3,59052 & 31,25736 & 29,21696 & \\
\hline
\end{tabular}

1 - Espessuras calculadas utilizando $V p=6,3 \mathrm{~km} / \mathrm{s}, \mathrm{Vs}=\mathrm{v}, 27811 \mathrm{~km} / \mathrm{s}, \mathrm{Vp} / \mathrm{Vs}=\mathbf{1 , 7 1}$ e $\sigma=0,240138$. Espessura crustal média de $34,7 \mathrm{~km}$.

2 - Espessuras calculadas utilizando $V p=6,3 \mathrm{~km} / \mathrm{s}, \mathrm{Vs}=3,579545 \mathrm{~km} / \mathrm{s}, \mathrm{Vp} / \mathrm{Vs}=\mathbf{1 , 7 6}$ e $\sigma=0,261632$. Espessura crustal média de $\mathbf{3 2 , 5} \mathrm{km}$

Tabela 2 - Modelo de velocidade inicial para a inversão dos dados de ARAB. A espessura da crosta foi fixada em $34 \mathrm{~km}$, de acordo com os valores obtidos, e a razão $V_{P} / V_{S}$ em 1,76

\begin{tabular}{|c|c|c|c|c|c|}
\hline $\mathbf{N}^{\circ}$ de Camadas & $\mathbf{V}_{\mathbf{P}}(\mathbf{k m} / \mathbf{s})$ & $\mathbf{V}_{\mathbf{s}}(\mathbf{k m} / \mathbf{s})$ & $\mathbf{V}_{\mathbf{p}} / \mathbf{V}_{\mathbf{s}}$ & $\begin{array}{c}\text { Espessura da Camada } \\
\mathbf{( k m})\end{array}$ & Razão de Poisson \\
\hline 1 & 6,0 & 3,4641 & 2,6900 & 7,0 & 0,261632 \\
\hline 2 & 6,3 & 3,6373 & 2,7860 & 13,0 & 0,261632 \\
\hline 3 & 6,5 & 3,7528 & 2,8500 & 14,0 & 0,261632 \\
\hline 4 & 8,0 & 4,6188 & 3,3300 & Semi Espaço & 0,261632 \\
\hline
\end{tabular}

